\title{
Understanding Growth Hormone Secretion and Short Stature
}

\author{
Milton Rodrigo Lafuente Covarrubias', Luis Fernando de Azevedo Piovezani', \\ Frederico Martins Cordeiro', William Cabrera Viana1, Mirella Hansen de Almeida², \\ Denise Rosso Tenório Wanderley Rocha ${ }^{1}$, Alberto Krayyem Arbex ${ }^{1,3}$ \\ ${ }^{1}$ Division of Endocrinology, IPEMED Medical School (IPEMED), São Paulo, Brazil \\ ${ }^{2}$ Fellow at the Joslin Medical Center, Boston, USA \\ ${ }^{3}$ Visiting Scientist, Harvard T. H. Chan School of Public Health, Harvard University, Boston, USA \\ Email: lafco4@hotmail.com
}

Received 24 December 2015; accepted 24 January 2016; published 28 January 2016

Copyright (C) 2016 by authors and Scientific Research Publishing Inc.

This work is licensed under the Creative Commons Attribution International License (CC BY). http://creativecommons.org/licenses/by/4.0/

(c) (i) Open Access

\begin{abstract}
Short stature is a clinical challenge in the daily practice of pediatric endocrinology, regarding the several technical, cultural and economic factors associated with its approach. This article intends to review the physiology of growth hormone secretion, the endocrine regulation of human growth and the clinical aspects of the diagnosis and treatment of short stature. It specifically analyses the treatment of short stature with growth hormone, along with its side effects, cost/benefit analysis and possible risks. A clinical case from a medical school is also described, intending a better understanding of this frequent ambulatory situation in endocrinology and pediatrics.
\end{abstract}

\section{Keywords}

\section{Growth Hormone, GH Treatment, Short Stature, Abnormal Growth, Children}

\section{Introduction}

The dynamics of the growth process are affected by intrinsic and extrinsic factors, which define not only the final height but also the rate and the growth spurt. Good pediatric care includes careful clinical monitoring of growth, which is a sensitive marker of health and well-being. The detection of unexplained acceleration or deceleration in the growth rate, or the adoption of a curve different from that expected from family background, requires investigation; changes in endocrine function are an important part of the investigation, but do not fully account for the differential diagnosis of abnormal growth.

This paper aims to offer comprehensive information for the detection and treatment of short stature due to 
growth hormone deficiency (GHD), while taking into account differential diagnosis relevant to clinical investigation of the problem. A clinical case followed by the IPEMED Medical School, located at São Paulo, Brazil, from the endocrinology ambulatory clinic was used for reference.

\section{Clinical Case}

An 8-year-old boy started receiving treatment for short stature in our endocrinology ambulatory clinic His background included a birth weight of $2600 \mathrm{~g}$ and height of $46 \mathrm{~cm}$, with a stay in the neonatal intensive care unit for 8 days for unclear reasons, being fed cow's milk, starting table food at 7 months of age, not being breastfed, and several admissions for pneumonia and a case of varicella. Vaccinations were up-to-date, and he does not take any continuous medication. His family background includes an apparently healthy mother with a height of 155 $\mathrm{cm}$ and a healthy father with a height of $175 \mathrm{~cm}$. The calculated target height is $171.5 \mathrm{~cm}(163-180 \mathrm{~cm})$. Differential screening was performed for possible causes of short stature, and Growth Hormone (GH) deficiency was detected, as shown in Table 1.

Treatment with GH was recommended. There was a delay in starting treatment due to financial reasons, and the family applied for coverage of high-cost medication through the Brazilian Unified Health System ("SUS"). For nearly 3 years, it was financially difficult to continue regular treatment, and difficult to obtain GH through the SUS. The lack of growth in the growth chart (Figure 1) indicates the period in which GH was not used.

In the context of this case, it is necessary to explain some concepts regarding short stature and the approach that should be followed in investigation and treatment.

In the first 2 years of extrauterine life, children adopt their own growth rate, which can be classified as precocious, normal, or delayed maturation. There are variations in pubertal development within this framework, with differences in age, onset of puberty, and the pubertal growth spurt, without necessarily indicating a pathological association.

Children with chronic diseases and short stature depend on the perceptions of caregivers when beginning assessment for the possible treatment of a stature deficit [1].

Genetic and racial factors are highly significant for the final stature and growth pattern in childhood and adolescence. It is also important to consider family stature, which corresponds to $\pm 2 \mathrm{SD}$ (approximately $\pm 10 \mathrm{~cm}$ ) of the family target stature, estimated by using the average height of the parents $+6.5 \mathrm{~cm}$ for male and $-6.5 \mathrm{~cm}$ for female children [2].

$$
\text { Family target stature }=\frac{(\text { father's height }+ \text { mother's height })+6.5 \mathrm{~cm}}{2}
$$

The family pattern is considered adequate if it lies within the 3rd and 97th percentiles of the family target stature or \pm 2 SD of the average for gender and chronological age. Hormones are essential for the growth process, but their interaction with genetic, nutritional, psychological, and social factors must be emphasized, because these will largely determine final stature. Genes determine cellular differentiation and the development of organs and tissues. Genes of the homeobox family, class Hox I, for example, participate in the embryonic modeling of the axial skeleton and limbs. Mutations in the SHOX genes in the pseudoautosomal region of the X chromosome determine bone dysplasia and short stature (Leri-Weill Syndrome). Haploinsufficiency of the SHOX gene causes short stature associated with Turner Syndrome [3].

Table 1. Stimulus tests results (performed at different times).

\begin{tabular}{cccc}
\hline TIME IN MINUTES & CLONIDINE & EXERCISE & INSULIN \\
\hline 0 & & 0.1 & 0.54 \\
15 & & 2.46 & 0.29 \\
20 & & & 1.04 \\
30 & 1.3 & 0.22 & 2.1 \\
40 & 3.4 & & 1.18 \\
45 & 2.3 & & 1.92 \\
60 & & & \\
\hline
\end{tabular}


CDC Growth Charts: United States

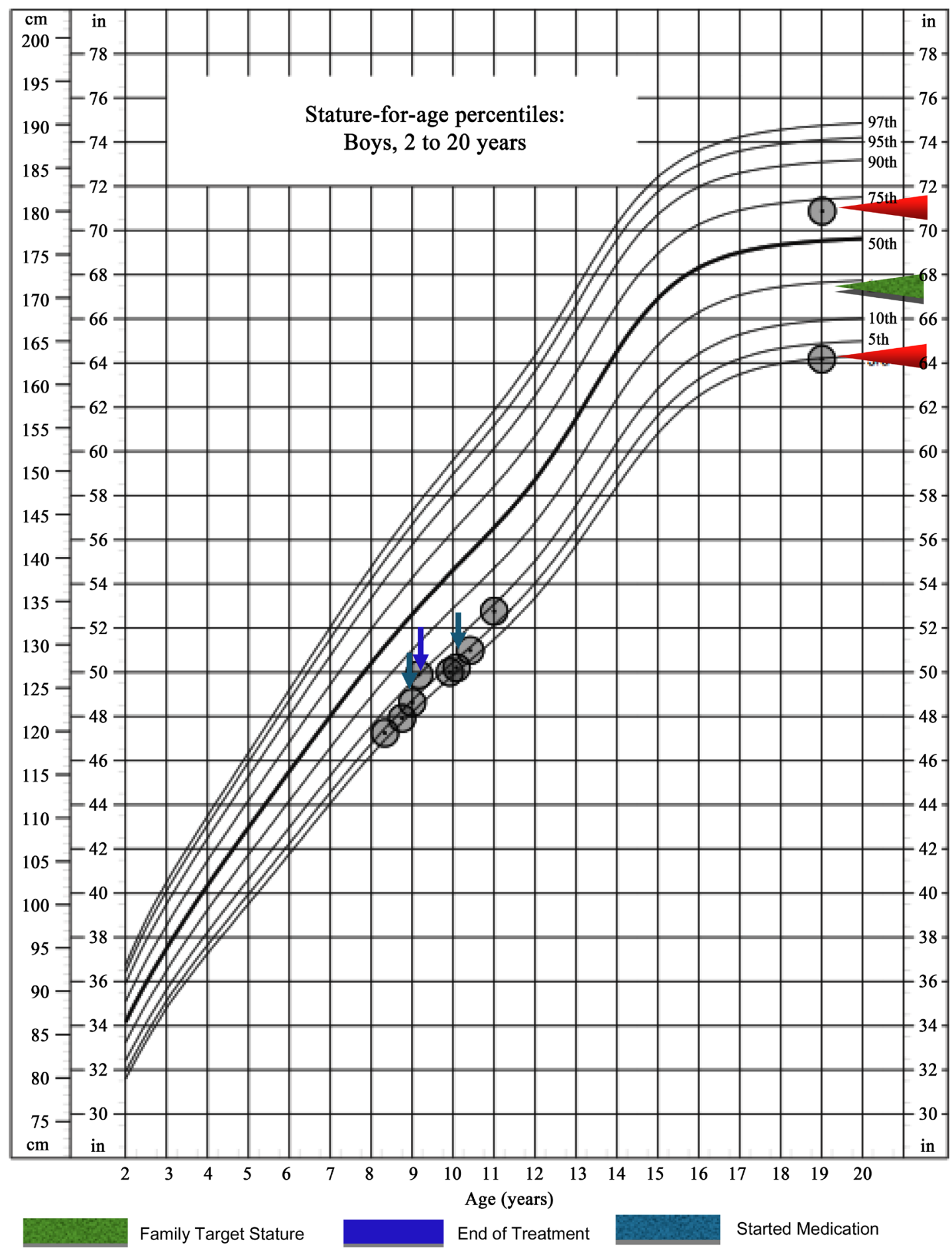

Figure 1. Response to GH treatment. The lack of growth whenever GH was not used is apparent.

\section{Regulation of Hypophyseal GH Secretion}

The gene for human GH, i.e., GH1, is located at $78 \mathrm{~kb}$ from the long arm of chromosome 17. It comprises 4 introns and 5 exons and is part of a group of 5 genes: the placental GH gene (GH-5), two genes associated with the 
placental lactogen hormone, and a gene that encodes for a protein similar to the placental lactogen hormone. The somatotrophs of the anterior pituitary control production of GH in the predominant form of a single-stranded chain of 198 amino acids, with two internal disulfide bonds. The molecular weight is $22 \mathrm{kDa}$, which corresponds to $75 \%$ of the GH supply. Between $5 \%$ and $10 \%$ are of $20 \mathrm{kDa}$ size, which results in alternative splicing. Secretion occurs in pulses, especially in sleep stages III and IV, with a half-life of 20-minute. Usually, 6 to 10 pulses occur in 24 hours, predominantly at night [4].

"GHR" is the specific GH receptor. The GHR gene is located at $87 \mathrm{~kb}$ from the short arm of chromosome 5. It has a 246 amino acid extracellular domain, a transmembrane component, and a cytoplasmic domain of 350 amino acids. Dimerization is necessary (coupling two receptors) in order to transmit the signal [5].

Intrauterine growth takes place at a rate of 1.2 to $1.5 \mathrm{~cm}$ per week, reaching a maximum of $2.5 \mathrm{~cm}$ per week in the middle of pregnancy (approximately 18 weeks), decreasing to $0.5 \mathrm{~cm}$ per week near term. The hormonal control in that phase is regulated by insulin-like growth factor-1 (IGF-1) and 2 (IGF-2). GH and thyroid hormone slightly affect in utero somatic growth [6].

At birth, the growth rate is both the most rapid and the rate that decreases the soonest during a child's development, with a growth of approximately $25 \mathrm{~cm}$ in the first year, decreasing to $15 \mathrm{~cm}$ in the second year; this coincides with the decrease in sex steroids after birth and the action of IGF in response to nutrition as the main factor responsible for GH production. This rate decreases after 4 years (early childhood), and is then replaced by a growth rate of 5 - $6 \mathrm{~cm}$ per year. Genetic "channeling" (decrease in the percentile of a tall baby from short parents or increase in the percentile of a short baby from tall parents) usually takes place until infants are 9 to 12 months old [7].

Rapid growth returns during adolescence, with rates of up to $15 \mathrm{~cm}$ per year. The age of skeletal maturation is earlier for girls than for boys. However, boys grow $13 \mathrm{~cm}$ taller before fusion of the growth plates. Normal puberty (9.5 to 14 years for boys and 7.5 to 13 years for girls) can present with a decreased growth rate in children with delayed maturation, while other children are entering a growth spurt [8].

Correct positioning when measuring stature or length and maintenance of precise records should be performed by a trained individual, as these are essential when analyzing growth with a proper growth chart. Children under 2 years old should be measured in supine position, with their legs fully extended using a T-ruler with a fixed part for the head and a mobile part for the feet. At 2 years old, they should be able to stand independently, and should be measured with a wall-mounted stadiometer. The length and stature should be measured 3 times, with maximum variation of $0.3 \mathrm{~cm}$. The average should be calculated and recorded. The occipitofrontal cephalic perimeter, the relationship between upper and lower body segments (S/I), and the arm span are useful when assessing short stature, tall stature, or pronounced growth disproportion. Therefore, an S/I ratio that is greater than expected indicates short stature caused by a genetic disorder; the ratio can be less than expected in short (e.g., those who have received spinal irradiation) and tall children (e.g., those with Marfan syndrome). Bone age (BA) can be used to assess maturation by using simple radiography of the left hand and wrist; it can also be used to quantify ossification of the trabecular bone taken at different points, comparing these with radiographic patterns for boys and girls. The assessment of BA should be carefully performed, as it assumes that one radiograph of the left hand represents the centers of ossification for the entire body, thus avoiding unnecessary exposure to radiation. It is more commonly used for comparison against standards published by Greulich and Pyle (G-P), measured from a small cohort of white North American children between 1931 and 1942. It is important to understand that these are old standards, with decreasing accuracy for 21st century children, as well as for children of other ethnicities or those with intrinsic skeletal dysplasia. However, they are the current reference standards for the assessment of bone development due to their practicality and simplicity of assessment.

Linear growth is considered to end when the growth rate is lower than $1.5 / 2.5 \mathrm{~cm} /$ year and/or bone maturation is between $97 \%$ - 98\%. These goals are usually reached at around $14-15$ years for girls and $16-17$ years for boys. However, body maturation (lean mass, body fat, and bone density) can continue up to the age of 30 [9].

Somatic development is not finished when growth ceases, and available studies show evidence indicating that GH is necessary in the postpubertal transition phase in order to reach normal adult stature [10].

\section{Prediction of Adult Stature and Parental Genetic Target}

Several methods were devised for the Prediction of Adult Height (PAH), and all agree that a delay in BA in relation to chronological age is directly proportional to the remaining growth potential. It is also accepted that as 
BA advances, adult height becomes more accurate. The most commonly used method is that of Bayley and Pinneau, which is based on the Atlas of Skeletal Development by G-P. It can be calculated from BA, chronological age, and current stature, by introducing semiquantitative weighting for chronological age. It is important to emphasize that all methods were based on data from normal children, without any evidence of accuracy for growth abnormalities [11].

\section{Endocrine Regulation of Growth}

All methods were based on data from normal children, without any evidence of accuracy for growth abnormalities. The complex interaction between stimulatory and inhibitory hormones influenced by afferent messages from the central and peripheral nervous systems determines the endocrine regulation of growth. In order to evaluate this regulation, in addition to the GH-IGF axis, gonadotropins/sexual steroids and thyroid function, nutritional deficits, psychosocial stress, and occult organic dysfunction, such as kidney or gastrointestinal diseases, should be assessed. The synthesis and secretion of GH occur in the anterior pituitary or adenohypophysis, which originates from the Rathke's pouch through invagination of the primitive pharyngeal epithelial floor between the 15th and 20th day of pregnancy [12].

Depending on the growth period, various endocrine systems regulate the process. During fetal life, the impact of nutrition, insulin, and IGF is more relevant than GH. In the first months of lactation, however, adequate nutrition will determine linear growth, as well as thyroid hormone, which is highly important in relation to GH, even if the same hormone is not relevant to the fetus. In early childhood, nutrition, $\mathrm{GH}$, and thyroid hormone are the bases for growth regulation. As puberty approaches, the levels of GH decrease, and increase significantly at the onset of puberty. This initiates the growth spurt, which would not be possible without GH [13].

Patterns of height and growth are controlled by a series of mechanisms that vary from childhood to early adulthood. Even though a child's length at birth seems to be affected by genetic components, the mother's size (determined by genes and environment), her behavior during pregnancy, and fetal health and nutrition are considered to be the main determinants of length at birth, while genetics, nutrition, and disease affect growth more strongly after birth. It is believed that growth in the first 2 years is more susceptible to environ-mental influence than later in childhood, which would then be mainly genetically determined [14].

\section{Diagnosis and Treatment of Abnormal Growth}

Childhood growth disorders often have the following characteristics: short stature with a normal growth rate (growth and skeletal maturation rate within normal parameters, short family/genetic stature), short stature with normal growth rate and evidence of lower previous rate (delay in growth with retardation of bone maturation), abnormal growth rate combined with or without short stature (systemic disease or hormone deficiency), and growth acceleration. Is required for the following cases [15]:

- Unexplained hypoglycemia, jaundice, or microphallus;

- Early signs of potential hypopituitarism, including GHD;

- Unexplained abnormally slow or fast growth;

- Growth rate consistently below 10th or above 95th percentile than that expected for age;

- Extremely short stature;

- Stature lower than the 1st percentile for age $(<-2.25 \mathrm{SD})$;

- Pattern and prognosis of growth divergent from that of the family;

- Estimation of stature (current stature percentile corrected for BA) differs significantly from PAH;

- Abnormal body proportions.

\section{Treatment with Growth Hormone}

\subsection{Rationale of Treatment}

In 1985, the FDA approved biosynthetic GH. Biological systems (Escherichia coli and recently mammalian cells) transplanted with GH genes ensure an almost unlimited GH supply and eliminates the risk of transmitting infections, such as those described in reported cases of Creutzfeldt-Jakob disease (CJD), a rare and fatal spongiform encephalopathy found in patients who received GH from pituitary glands contaminated with subviral particles from corpses. Virtually all GH prescribed today is r-GH, which has 191 amino acids (recombinant GH). Therapy 
with GH might be recommended after assessing the cause of the growth problem, parental concerns, and probability of success. Efforts to increase self-esteem through parental support, careful selection of activities, and psychotherapy may possibly be more beneficial than injectable GH therapy. Retire et al. analyzed data from 1258 patients treated with GH who had nearly reached adult height in order to determine which factors were contributory. The results show that Caucasian patients with GHD who were treated with GH reached a nearly adult height of 0.8 and $1.0 \mathrm{SD}$ in men and women, respectively; in patients with multiple pituitary hormone deficiencies, the nearly adult heights were 0.7 and $1.1 \mathrm{SD}$ in men and women, respectively. Japanese patients with GHD, however, reached much lower nearly adult heights (1.6 SD in men and 2.1 SD in women), even though for the population [16].

After the first 6 months of life, it is possible to determine the pattern of the growth rate from the lower part of the normal growth curve. The BA is delayed and (if hypothyroidism is not detected) equal to the stature age. The distribution of fat increases and muscle mass decreases, identified by the delay in gross motor development. During growth, the closing of the fontanelle is delayed, hair is thin and fine, and the growth of nails is slow. If untreated, GHD adult stature can remain between -3.1 and -4.7 in the standard deviation score. In $40 \%$ to $70 \%$ of patients diagnosed with idiopathic or isolated GHD (IGHD), repeated exams are normal, especially in the immediate prepubertal period, due to the physiological decrease in GH in that period. Reduced serum levels of IGF-1, IGF-2 and insulin-like growth factor binding protein (IGFBP)-3, and elevated or normal levels of GH suggest an IGH diagnosis, considering the following: basal serum GH above $10 \mathrm{mU} / \mathrm{l}$ (approximately $5 \mu \mathrm{g} / \mathrm{l}$ ), basal serum IGF-1 lower or equal to $50 \mu \mathrm{g} / \mathrm{l}$, lower stature EDP at -3 , serum GH receptor binding protein (GHBP) lower than 10\%, and elevation of IGF-1 levels after the administration of GH. Lower GHBP serum levels also suggest an IGH diagnosis, although this entity can develop with normal GHBP levels. Thus, a definite IGH diagnosis requires classic phenotype, reduced IGF-1 and IGFBP-3 serum levels, and identification of an abnormality in the GH receptor gene [17] [18].

The treatment of IGF-1 deficiency starts with a therapeutic GH test. Currently, a daily regime with subcutaneous administration is preferred. In the USA, daily doses of 0.04 or $0.05 \mathrm{mg} / \mathrm{kg} / \mathrm{day}$ are administered, and are started as early as possible. Even in cases where one wishes to postpone the injection treatment in young children in order to avoid discomfort and inconvenience, evidence shows that early identification, diagnosis, and treatment for severe GH deficiencies should be recommended in order to improve growth potential. Regardless of the regime chosen, the best response to GH is seen in the first year of treatment, gradually decreasing with time. Seasonal variation is also observed, with peaks during summer and nadirs during winter (North American population) [19].

There is no consensus regarding the most efficient dosage and frequency for GH administration in adolescents. Conventionally, 0.18 to $0.35 \mathrm{mg} / \mathrm{kg} /$ week is recommended, although there are indications that doses of 0.7 $\mathrm{mg} / \mathrm{kg} /$ week would increase the growth rate in this age group without any evident adverse effects. GH replacement, after reaching target height in young adults with GHD, is associated with a significant increase in the thickness of cortical bone. The reduction observed in the intra-bone diameter of patients treated with GH in this study suggests that the increase results in the growth of endosteal rather than periosteal bone. While there is no sole cause for bone fragility, smaller or thinner trabeculae and thin cortices all play a role in lowering maximum bone density [20].

For idiopathic short stature (ISS) should be discussed with the child and parents. These include observation and safety, GH therapy, and low-dose hormone therapy. Clinical observation is a reasonable strategy, supported by a lack of evidence linking short stature with psychological dam-age, or evidence for long-term psychological benefit after GH therapy; the expectation of eventual approximation of adult height to familial average height should be discussed [21].

\subsection{Cost/Benefit Analysis}

The maximum average height gain associated with GH treatment in children with Idiopathic Short Stature (ISS) is uncertain, and the costs are of 10,000 - 20,000 US Dollars/cm. However, the short- and long-term benefits for the individual and society are not clear. It is not known whether and how an increase in height affects life quality. Thus, GH treatment in children with ISS should be considered in the context of healthcare cost, specifically for the parents. Thus far, data showing an improvement in life quality and better psychological health, among other factors, have not been collected in well-controlled studies. Therefore, the recommendations for GH treatment should be 
balanced against the high cost of therapy [22].

\subsection{Duration of GH Treatment}

There are two approaches regarding the duration of treatment. One proposes that treatment should stop when nearly adult height is reached (growth rate of $2 \mathrm{~cm} /$ year and/or BA of 16 years for boys and 14 for girls). Alternatively, therapy can be interrupted when the height is within the normal adult level (above 2 SD) or when another cohort is reached for the adult reference population (for example, in Australia, the 10th percentile; in other locations, the 50th percentile). The interruption of therapy is influenced by the satisfaction of the patient/family with the results, by a cost-benefit analysis, or when the child wishes to stop for another reason [23].

\subsection{Potential Adverse Effects of GH}

The potential secondary effects in ISS children treated with GH are similar to those described in literature for children receiving GH therapy for other reasons. However, the frequency of adverse effects is usually lower. Individuals with a family background of short stature usually do not respond satisfactorily to GH therapy when compared to individuals with a different background. Clinical and laboratory presentations are the most important markers for diagnosing GHD. Results of functional GH tests depend on the assay used, the pubertal and nutritional state of the child, and the GH secretion pattern before the test. These tests are difficult to reproduce [23].

Although there is great similarity between the amounts of IGF-I and IGFBP-3 in GHD children when compared to normal children, these measurements are reasonably specific and useful if combined with other diagnostic criteria. Abnormal results of pituitary RNM indicate a relatively high probability that GHD will persist in adulthood, and suggests that a deficiency in the posterior pituitary gland might manifest later in life. Children with GHD and a GHD family history should be evaluated for GH1 and GHRHR mutations. Other genetic tests are still not widely applicable when diagnosing GHD, although these may contribute to diagnosis in the future [24].

\section{Conclusions}

Short stature due to growth hormone deficiency is a complex clinical situation that requires expertise, knowledge regarding the history of disease and a thorough analysis of the available treatment options, according to the best scientific evidences, avoiding off-label therapies or unproved alternatives.

Its diagnosis is made by excluding other possible causes of short stature, along with laboratory tests as IGF-1 levels and bone age $\mathrm{X}$-ray test.

When GH treatment is an available tool, it should be handled with knowledge and carefully, regarding its cost-benefit features, the need of frequent follow-ups and lab control tests, to assess the effectiveness and safety of this treatment, which varies from one patient to the other.

Short stature still poses a major challenge in the daily clinical practices nowadays, especially regarding pediatrics and in pediatric endocrinology.

\section{Acknowledgements}

We would like to thank IPEMED Brazil post graduates for their dedication to Endocrinology study and further research.

\section{References}

[1] Al-Uzri, A., Matheson, M. and Gipson, D. (2013) The Impact of Short Stature on Health-Related Quality of Life in Children with Chronic Kidney Disease. Journal of Pediatrics, 163, 736-741. http://dx.doi.org/10.1016/j.jpeds.2013.03.016

[2] Wilson, T., Rose, S., Cohen, P., et al. (2003) Update of Guidelines for the Use of Growth Hormone in Children: The Lawson Wilkins Pediatric Endocrinology Society Drug and Therapeutics Committee. Journal of Pediatrics, 143, 415421. http://dx.doi.org/10.1067/S0022-3476(03)00246-4

[3] Stevens, A., Clayton, P., Tato, L., et al. (2014) Pharmacogenomics of Insulin-Like Growth Factor-I Generation during GH Treatment in Children with GH Deficiency or Turner Syndrome. The Pharmacogenomics Journal, 14, 54-62. http://dx.doi.org/10.1038/tpj.2013.14 
[4] Boguszewski, C., Lacerda, C., et al. (2013) Reappraisal of Serum Insulin-Like Growth Factor-I (IGF-1) Measurement in the Detection of Isolated and Combined Growth Hormone Deficiency (GHD) during the Transition Period. Arquivos Brasileiros de Endocrinologia \& Metabologia, 57, 9. http://dx.doi.org/10.1590/S0004-27302013000900006

[5] Carel, J.C., Ecosse, E., Landier, F., et al. (2012) Long-Term Mortality after Recombinant Growth Hormone Treatment for Isolated Growth Hormone Deficiency or Childhood Short Stature: Preliminary Report of the French SAGhE Study. Journal of Clinical Endocrinology \& Metabolism, 97, 416-425. http://dx.doi.org/10.1210/jc.2011-1995

[6] Kalina, M., Kalina-Faska, B. and Gruszczyńska, K. (2012) Usefulness of Magnetic Resonance Findings of the Hypothalamic-Pituitary Region in the Management of Short Children with Growth Hormone Deficiency: Evidence from a Longitudinal Study. Child's Nervous System, 28, 121-127. http://dx.doi.org/10.1007/s00381-011-1594-7

[7] Cohen, P., Rogol, A.D., Deal, C.L., et al. (2008) Consensus Statement on the Diagnosis and Treatment of Children with Idiopathic Short Stature: A Summary of the Growth Hormone Research Society, the Lawson Wilkins Pediatric Endocrine Society, and the European Society for Paediatric Endocrinology Workshop. Journal of Clinical Endocrinology \& Metabolism, 93, 4210-4217. http://dx.doi.org/10.1210/jc.2008-0509

[8] Carrascosa, A., Fernández, J.M., Ferrández, A., et al. (2011) Estudios Españoles de Crecimiento 2010. Revista Española Endocrinología Pediátrica, 2, 59-62.

[9] Cohen, P., Weng, W., Rogol, A., et al. (2014) Dose-Sparing and Safety-Enhancing Effects of an IGF-I-Based Dosing Regimen in Short Children Treated with Growth Hormone in a 2-Year Randomized Controlled Trial: Therapeutic and Pharmacoeconomic Considerations. Clinical Endocrinology, 81, 71-76. http://dx.doi.org/10.1111/cen.12408

[10] Álvarez-Escolá, C., Fernández-Rodríguez, E., Recio-Córdovac, J.M., et al. (2013) Consensus Document of Neuroendocrinology Area of Knowledge of the Spanish Society of Endocrinology and Nutrition for Addressing Hypopituitarism during the Transition. Endocrinología y Nutrición, 61, 68.e1-68.e11. http://dx.doi.org/10.1016/j.endonu.2013.08.001

[11] Widen, E., Ripatti, S., Cousminer, D., Surakka, I., Lappalainen, T., Järvelin, M.-R., et al. (2010) Distinct Variants at LIN28B Influence Growth in Height from Birth to Adulthood. The American Journal of Human Genetics, 86, 773-782. http://dx.doi.org/10.1016/j.ajhg.2010.03.010

[12] Tauber, M., Berro, B., Delagnes, V., Lounis, N., Jouret, B., Pienkowski, C., Oliver, I. and Rochiccioli, P. (2003) Can Some Growth Hormone (GH)-Deficient Children Benefit from Combined Therapy with Gonadotropin-Releasing Hormone Analogs and GH? Results of a Retrospective Study. The Journal of Clinical Endocrinology \& Metabolism, 88, 1179-1183. http://dx.doi.org/10.1210/jc.2002-020974

[13] Hogler, W. and Shaw, N. (2010) Childhood Growth Hormone Deficiency, Bone Density, Structures and Fractures: Scrutinizing the Evidence. Clinical Endocrinology, 72, 281-289. http://dx.doi.org/10.1111/j.1365-2265.2009.03686.x

[14] Paternoster, L., Howe, L., Tilling, K., Weedon, M.N., Freathy, R.M., Frayling, T.M., et al. (2011) Adult Height Variants Affect Birth Length and Growth Rate in Children. Human Molecular Genetics, 20, 4069-4075. http://dx.doi.org/10.1093/hmg/ddr309

[15] Courtillot, C., Baudoin, R., Du Souich, T., Saatdjian, L., Tejedor, I., Pinto, G., Léger, J., Polak, M., Golmard, J.-L., Touraine, P. and on Behalf of the Transition GHD Group (2013) Monocentric Study of 112 Consecutive Patients with Childhood Onset GH Deficiency around and after Transition. European Journal of Endocrinology, 169, 587-596. http://dx.doi.org/10.1530/EJE-13-0572

[16] Reiter, E., Price, D., Wilton, P., Albertsson-Wikland, K. and Ranke, M.B. (2013) Effect of Growth Hormone (GH) Treatment on the Near-Final Height of 1258 Patients with Idiopathic GH Deficiency: Analysis of a Large International Database. The Journal of Clinical Endocrinology \& Metabolism, 91, 2047-2054. http://dx.doi.org/10.1210/jc.2005-2284

[17] Petkovic, V., Godi, M., Lochmatter, D., Eblé, A., Flück, C.E., Robinson, I.C. and Mullis, P.E. (2010) Growth Hormone (GH)-Releasing Hormone Increases the Expression of the Dominant-Negative GH Isoform in Cases of Isolated GH Deficiency due to GH Splice-Site Mutations. Endocrinology, 151, 2650-2658. http://dx.doi.org/10.1210/en.2009-1280

[18] Potic, A., Brais, B., Choquet, K., Schiffmann, R. and Bernard, G. (2012) 4H Syndrome with Late-Onset Growth Hormone Deficiency Caused by POLR3A Mutations. Archives of Neurology, 69, 920-923. http://dx.doi.org/10.1001/archneurol.2011.1963

[19] Lee, J., Yoon, J., Kang, M., Lee, Y.A., Lee, S.Y., Shin, C.H. and Yang, S.W. (2013) Influence of Body Mass Index on the Growth Hormone Response to Provocative Testing in Short Children without Growth Hormone Deficiency. Journal of Korean Medical Science, 28, 1351-1355. http://dx.doi.org/10.3346/jkms.2013.28.9.1351

[20] Hyldstrup, L., Conway, G.S., Racz, K., Keller, A., Chanson, P., Zacharin, M., Lysgaard, A.L., Andreasen, A.H. and Kappelgaard, A.-M. (2012) Growth Hormone Effects on Cortical Bone Dimensions in Young Adults with ChildhoodOnset Growth Hormone Deficiency. Osteoporosis International, 23, 2219-2226. http://dx.doi.org/10.1007/s00198-011-1854-0 
[21] Allen, D. and Cuttler, L. (2013) Short Stature in Childhood-Challenges and Choices. The New England Journal of Medicine, 368, 1220-1228. http://dx.doi.org/10.1056/NEJMcp1213178

[22] Donoso Sanz, M., Díaz Cerezo, S., Oyagüez Martín, I. and Casado Gómez, M.A. (2012) Impacto presupuestario de la utilización de hormona de crecimiento de la edad pediátrica a la adulta. Farmacia Hospitalaria, 36, 3-10. http://dx.doi.org/10.1016/j.farma.2010.11.004

[23] Franke, D., Živičnjak, M. and Ehrich, J. (2009) Growth Hormone Treatment of Renal Growth Failure during Infancy and Early Childhood. Pediatric Nephrology, 24, 1093-1096. http://dx.doi.org/10.1007/s00467-009-1190-1

[24] Butler, M., Roberts, J., Hayes, J., Tan, X. and Manzardo, A.M. (2013) Growth Hormone Receptor (GHR) Gene Polymorphism and Prader-Willi Syndrome. American Journal of Medical Genetics Part A, 161, 1647-1653. http://dx.doi.org/10.1002/ajmg.a.35980 